\title{
Advance directive preferences of patients with chronic and terminal illness towards end of life decisions: a sample from Saudi Arabia
}

Salim Baharoon, ${ }^{1}$ Mohsen Alzahrani, ${ }^{2}$ Eiman Alsafi, ${ }^{3}$ Laila Layqah, ${ }^{4}$ Hamdan Al-Jahdali ${ }^{5}$ and Anwar Ahmed ${ }^{6}$

${ }^{1}$ Intensive Care Department; ${ }^{2}$ Oncology Department; ${ }^{3}$ Quality Management Department, King Saud Chest Specialty Hospital, Riyadh, Saudi Arabia. ${ }^{4}$ Research Office; ${ }^{5}$ Pulmonary Division; ${ }^{6}$ Epidemiology and Biostatistics Department, King Abdullah International Medical Research Centre, King Saud Bin Abdulaziz University for Health Sciences, National Guard Health Affairs, Riyadh, Saudi Arabia. (Correspondence to: Salim Baharoon: baharoon@ hotmail.com).

\begin{abstract}
Background: Advance directives towards end of life decisions are seldom used among Arabs.

Aims: This study aimed at investigating advance care preferences among a sample of Arab patients.

Method: This cross-sectional study was undertaken over the period March 2012-March 2013 on a sample of 300 patients with chronic illness in King Fahad National Guard Hospital, Riyadh, a major tertiary care hospital in Saudi Arabia.

Results: Mean age of patients in the study was 48.7 years (standard deviation 16.4). There were 104 patients on haemodialysis, 73 with advanced malignancy, 81 with chronic liver disease and 35 with chronic respiratory disease. More than $80 \%$ of the respondents felt that the physician should make the decision about cardiopulmonary resuscitation. Over $60 \%$ wished to remain at home when their condition deteriorated to impending death. There were no significant correlations between the patients' end of life decision preferences and religiosity, quality of life, disease duration, or other demographic characteristics.

Conclusion: Despite a significant lack of knowledge among our participants regarding resuscitation, a majority of patients with chronic illness were willing to discuss the options and were capable of making advance directive plans regarding their health status.

Keywords: advance directives, end of life care, Saudi Arabia, chronic illness

Citation: Baharoon S; Alzahrani M; Alsafi E; Layqah L; Al-Jahdali H; Ahmed A. Advance directive preferences of patients with chronic and terminal illness towards end of life decisions: a sample from Saudi Arabia. East Mediterr Health J. 2019;25(11):791-797. https://doi.org/10.26719/emhj.19.038 Received: 01/08/17; accepted: 11/02/18

Copyright (C) World Health Organization (WHO) 2019. Some rights reserved. This work is available under the CC BY-NC-SA 3.o IGO license https:// creativecommons.org/licenses/by-nc-sa/3.o/igo
\end{abstract}

\section{Introduction}

Advance directive planning offers patients the opportunity to express and document their treatment preferences while they are competent to do so $(1,2)$. Research has shown that patients prefer to discuss advance directives early in the patient-physician relationship (2). In Western culture, patients prefer to discuss their advance directives at a time when they can make an informed decision and usually advance care planning decisions are introduced and made in the outpatient setting. In the United States of America, up to $70 \%$ of community-dwelling older adults have completed an advance directive. However, families in other cultures may try to protect their loved ones from the emotional stress of directly discussing death or end of life care (3). For example, advance directives are rarely practised in East Asia. However, this belief that some culture may not be receptive to the idea of advance directives may not be entirely true. Wong et al. found that it was feasible to discuss an advance directive with Chinese patients with advanced malignancies, a culture previously thought not to be acceptable to advance directive discussions (4).

Although the concept of advance directives is deeprooted in Islamic teaching, it is seldom practised in the setting of end of life health care planning among Arab patients, or even among other Muslims (5). Among Saudi citizens there is a strong belief that open discussion of serious illness may cause unnecessary depression or anxiety to the patient $(2,3)$. Relatives may even require physicians to give a patient hope in the face of terminal illness or may request that the patient is not informed of the seriousness of their condition $(6,7)$. Some believe that care may become less optimal when they involve end of life care planning, including advance directives. Some investigators found that a pre-admission "do not resuscitate" advance directive is associated with higher rates of pneumonia, sepsis, myocardial infarction, and death (8).

Physicians often utilize technical terms to minimize or obscure the seriousness of the disease and its prognosis $(4,5)$. Some investigators concluded that implementing a programme to increase physician opportunity to discuss end of life care with their patients, and improve residents' confidence in leading discussions regarding advance care directives, led to more patients expressing interest in talking about their wishes (9).

Saudi Arabian family members, particularly parents, feel that they are responsible for their relatives' welfare and may request extraordinary measures, even if the situation is futile $(4,5)$. Such decisions taken on behalf of the patient may subject them to overzealous use of life-sustaining procedures that prolong suffering 
and compromise both dignity and quality of life. If informed of the seriousness of their illness or the futility of interventions at the outset, a patient might decide to avoid additional suffering. Completion of advance directives is associated with a lower likelihood of receiving unnecessary life-sustaining treatments, reducing suffering and providing early closure (10).

Factors influencing decision-making in end of life care in the Arab world are largely unknown. There is also a lack of data on the prevalence of advance directives in Arab countries and how frequently they are used to dictate decision-making in medical practice. Furthermore, there is very little information available on Arab patients' preferences and wishes regarding end of life care. Our patients and their relatives usually prefer not to discuss these issues in advance. Such discussions are held in some quarters to be a bad omen.

This study addresses the important aspect of end of life health care planning in Arab patients with chronic incurable disease.

\section{Methods}

This was a cross-sectional, observational descriptive study undertaken over the period from March 2012 to March 2013 in King Abdulaziz Medical City, King Fahad National Guard Hospital a major tertiary hospital in Riyadh, Saudi Arabia.

An Arabic language structured questionnaire composed of 4 sections was developed by investigators. The first 3 sections concerned demographic data, including knowledge about cardio-pulmonary resuscitation (CPR), mechanical ventilation and intensive care unit (ICU) admission. The fourth section contained various end of life decision scenarios followed by questions on personal wishes and preferences related to these scenarios. These scenarios addressed medical interventions, CPR, ICU admission, and who should be the decision-maker if the patient was not in a condition to be able to make such decisions themselves.

Self-perception of religiosity was assessed using a visual analogue scale that ranged from o (not religious at all) to 100 (very religious). Similarly, perception of quality of life was assessed using a visual analogue scale that ranged from o (poor quality of life) to 100 (excellent quality of life).

The questionnaire was initially tested among 20 patients recruited from a general medicine clinic to evaluate the clarity and understanding of the questions and to correct any ambiguity or vagueness. Only minor wording in some of the Arabic questions was changed. The Research and Ethics Committee of King Fahad National Guard Hospital Riyadh approved this study.

Included in the study were patients on haemodialysis for more than 2 years if they were not transplant candidates, patients with chronic respiratory failure requiring home oxygen, patients with advanced terminal malignancy not amenable to chemotherapy, patients with advanced congestive cardiac failure with a New York Heart Association (NYHA) classification of III and IV and patients with advanced liver cirrhosis with Child-Pugh class $\mathrm{C}$ who are not transplant candidates. Participants had to pass a Mini-Mental Examination before completing the questionnaire. The Mini-Mental State Examination is a 30-point questionnaire that is used to measure cognitive impairment (11). This examination has previously been translated to Arabic and validated (12). Medical records were also examined for a past history of dementia or confusion. Patients with past history of dementia were excluded.

Quality of life was measured using the Arabic language version of the EQ-5D score; this is generic standardized measure of health status that provides a simple descriptive profile and a single index value to measure health-related quality of life (13). It is one of the most commonly used tools for this purpose and has been translated into more than 170 languages. We used the 5-level response version (EQ-5D-5L), which has been shown to provide significantly increased reliability and sensitivity (discriminatory power), while maintaining feasibility and potentially reducing ceiling effects compared to the earlier 3-level version $(14,15)$. The descriptive system of EQ-5D-5L comprises the same 5 dimensions as the EQ-5D-3L (mobility, self-care, usual activities, pain/discomfort, anxiety/depression). However, each dimension now has 5 levels of responses. A visual analogue scale was used to measure participants' self-perception of religiosity.

The purpose of the study was explained to all the patients by the study coordinator. Participants were assured that their information would be confidential, not documented in their chart and would only be used for research purposes. They were also advised that a decision not to participate would not influence their current or future care plan. Patients who agreed to be enrolled in the study were asked to complete the entire questionnaire.

All data were entered into Microsoft Excel and then transferred to SPSS, version 13, for analysis. Categorical sample characteristics were reported by frequency and percent; continuous sample characteristics were reported by mean and standard deviation. Patients' knowledge about cardiac resuscitation, intubation and mechanical ventilation were summarized by frequency and percent.

\section{Results}

The number needed was calculated based on the percentage of patients who would like to choose advanced directives, about $25-30 \%$. Of the 354 patients interviewed, 300 agreed to participate and completed the questionnaire (85\% response rate). Demographic characteristics are described in Table 1. The mean age of the patients was 48.7 (standard deviation 16.4 ) years, $51.3 \%$ were male and $85.0 \%$ were Saudi Arabian. More than half of the participants were unemployed and one-third were retired; the majority of retired patients had been retired for more than 2 years. There were 104 patients undergoing haemodialy- 
sis, 81 with chronic liver disease, and 73 with advanced malignancy (Table 1). For self-assessment of religiosity, only $22 \%$ considered themselves highly religious (score $\geq 70$ ). On the visual analogue scale for best imaginable health state, $78 \%$ scored themselves $<70$ (Table 1).

Around $65 \%$ of our participants had been admitted to hospital at least once in the preceding 2 years, with $36 \%$ being admitted to the ICU at least once (Table 1). Just over half of the participants had visited friends or family members in an ICU. Around $46 \%$ reported some mobility problems but only $3 \%$ were bedbound. When asked about pain and discomfort, $48.7 \%$ of respondents were in at least moderate pain or discomfort while pain and discomfort were described as severe by a further $12.7 \%$ (Table 2).

When asked about their condition, $20 \%$ of patients perceived themselves as a burden to their families. Only $25.3 \%$ knew that their disease was incurable while $54.7 \%$ thought it was curable and $20.0 \%$ stated their doctors did not discuss the prognosis of their disease with them directly. The majority of respondents had no or only limited information about CPR or mechanical ventilation (Table 3).

We found that $85 \%$ of our participants felt that the physician should be the one to make decisions about resuscitative measures on their behalf if they were not able to decide for themselves. Only $15 \%$ wanted the decision to be made by members of their family. However, when the question was posed more directly in the form: "Would you agree with your physician deciding not to do cardiac resuscitation if your heart stopped?", only $27 \%$ agreed, $48 \%$ disagreed and $25 \%$ did not know.

The number of patients who would undergo CPR was dependent on the expected outcome of the resuscitation: $85 \%$ were in favour of resuscitation if they would recover completely from their acute illness and become independent after recovery; with around 5\% stating they would prefer not to be resuscitated. The numbers in favour of resuscitation dropped with decreasing independence as an outcome: only $40 \%$ were in favour of resuscitation if they would be left with permanent brain damage.

When the patients were asked about their preference for the setting of terminal care if their condition deteriorated to impending death, $63 \%$ wished to remain at home. This increased to $78 \%$ if they were supported with medication and $81 \%$ if they were supported with home health care services.

When the patients were asked about their preference for the setting of care once transferred to a hospital and then finding out that hospitalization and medical intervention would not improve their condition, 59\% said they would prefer to go back home to die while $31 \%$ wanted to remain in the hospital. While $58 \%$ would prefer to stay in the hospital for palliative treatment, 50\% wanted to be admitted to ICU for aggressive measures, regardless of the outcome.

When given the scenario "If admission to ICU/ intubation would mean that I would lose independence, I would prefer not to be admitted to ICU", $45 \%$ agreed with the statement while $16 \%$ were undecided and $39 \%$ wished

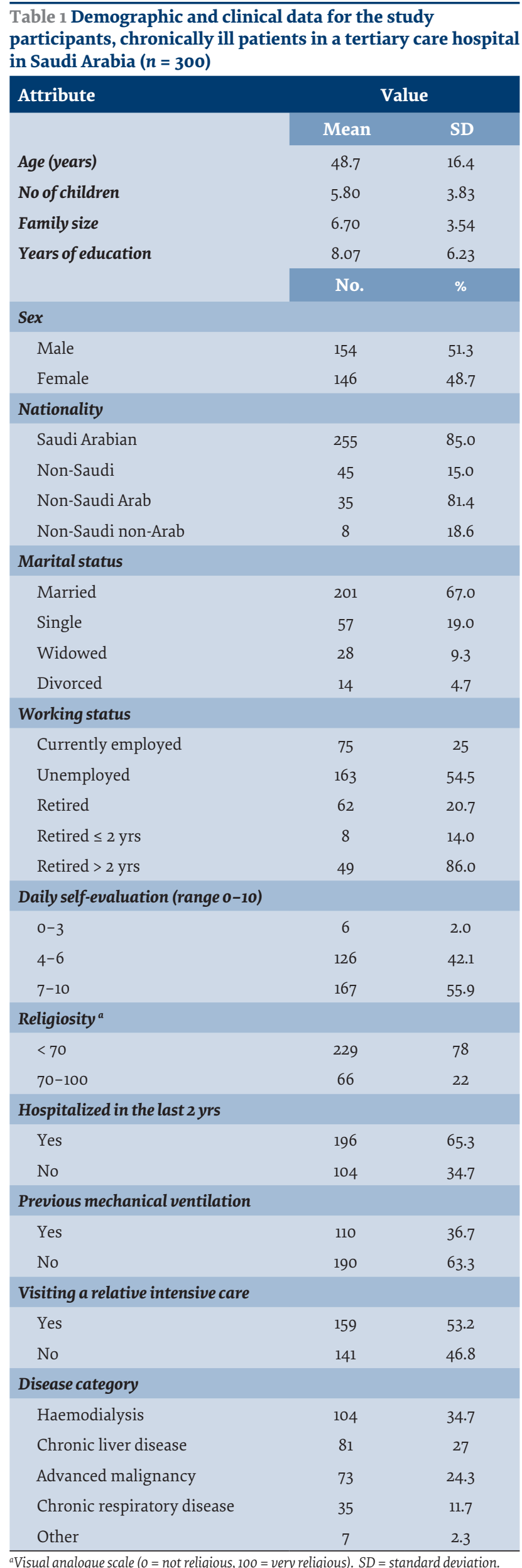

${ }^{a}$ Visual analogue scale ( $0=$ not religious, $100=$ very religious). $S D=$ standard deviation. 


\begin{tabular}{|c|c|c|}
\hline \multicolumn{3}{|c|}{$\begin{array}{l}\text { Table } 2 \text { Self-assessment of functionality and quality of life } \\
\text { among chronically ill patients in a tertiary care hospital in } \\
\text { Saudi Arabia }(n=300)\end{array}$} \\
\hline Parameter & No. & $\%$ \\
\hline \multicolumn{3}{|l|}{ Mobility } \\
\hline I have no problems walking about & 152 & 50.7 \\
\hline I have some problems walking about & 139 & 46.3 \\
\hline I am confined to bed & 9 & 3.0 \\
\hline \multicolumn{3}{|l|}{ Self-care } \\
\hline I have no problems with self-care & 225 & 75.0 \\
\hline I have some problems washing or dressing myself & 57 & 19.0 \\
\hline I am unable to wash or dress myself & 18 & 6.0 \\
\hline \multicolumn{3}{|l|}{ Usual activities } \\
\hline $\begin{array}{l}\text { I have no problems with performing my usual } \\
\text { activities }\end{array}$ & 160 & 53.3 \\
\hline $\begin{array}{l}\text { I have some problems with performing my usual } \\
\text { activities }\end{array}$ & 89 & 29.7 \\
\hline I am unable to perform my usual activities & 51 & 17.0 \\
\hline \multicolumn{3}{|l|}{ Pain/discomfort } \\
\hline I have no pain or discomfort & 116 & 38.7 \\
\hline I have moderate pain or discomfort & 146 & 48.7 \\
\hline I have extreme pain or discomfort & 38 & 12.7 \\
\hline \multicolumn{3}{|l|}{ Anxiety/depression } \\
\hline I am not anxious or depressed & 156 & 52.0 \\
\hline I am moderately anxious or depressed & 118 & 39.3 \\
\hline I am extremely anxious or depressed & 26 & 8.7 \\
\hline
\end{tabular}

to go to ICU. However, $67 \%$ of this last group agreed that they would not want life-sustaining measures if they were unlikely to recover.

More than half the respondents (55\%) would like their families to participate in the decision-making for end of life care while $25 \%$ wanted to be the sole decision-makers.

Neither religiosity nor quality of life, disease duration, marital status, family size, number of children, working status, education level, sex or age had any significant impact on the patients' end of life preferences.

\section{Discussion}

This is the first descriptive study evaluating the preferences for resuscitation among a sample of Arab (Saudi Arabian) population with a variety of chronic and advanced terminal illnesses. Previous research from Saudi Arabia highlighted the health care provider's views on issues relating to CPR (16-18).

Preferences for life-supportive care in various circumstances can only be learnt by talking to patients. There are many potential benefits from discussing preferences for end of life care and formulating advance directives; including reducing the cost of ICU care and concurring with the patient's wishes for treatment.

Less than $8 \%$ of the sampled population understood the meaning or potential outcome of CPR or intubation and mechanical ventilation and their relevance to their

\begin{tabular}{|c|c|c|}
\hline \multicolumn{3}{|c|}{$\begin{array}{l}\text { Table } 3 \text { Knowledge and awareness of resuscitative measures } \\
\text { among chronically ill patients in a tertiary care hospital in } \\
\text { Saudi Arabia }(n=300)\end{array}$} \\
\hline Knowledge topic & No. & $\%$ \\
\hline \multicolumn{3}{|l|}{ Cardiac resuscitation } \\
\hline Nothing at all & 210 & 70.0 \\
\hline Not enough information to make any decisions & 67 & 22.3 \\
\hline A little information, including how it is done & 13 & 4.3 \\
\hline $\begin{array}{l}\text { Reasonable information, including how it is done } \\
\text { and some complications }\end{array}$ & 3 & 0 \\
\hline $\begin{array}{l}\text { A lot of information, including how it is done, } \\
\text { possible complications and outcomes and who may } \\
\text { benefit }\end{array}$ & 7 & 2.4 \\
\hline \multicolumn{3}{|l|}{ Intubation and mechanical ventilation } \\
\hline Nothing at all & 190 & 63.3 \\
\hline Not enough information to make any decisions & 88 & 29.3 \\
\hline A little information, including how it is done & 14 & 4.7 \\
\hline $\begin{array}{l}\text { Reasonable information, including how it is done } \\
\text { and some complications }\end{array}$ & 3 & 1.0 \\
\hline $\begin{array}{l}\text { A lot of information, including how it is done, } \\
\text { possible complications and outcomes and who may } \\
\text { benefit }\end{array}$ & 5 & 1.7 \\
\hline
\end{tabular}

conditions. This reflected a poor approach to delivering adequate medical knowledge to patients with advanced and chronic illness. It is important to provide our patients with a description of their disease, including its symptoms and signs, and also an understanding of the natural history of the illness. It was not surprising then to see most of our patients $(85 \%)$ preferring their physician to make medical decisions on end of life care on their behalf.

We, as health care providers, think our culture does not encourage staying at home when sick with terminal illness. On the contrary, far more patients actually prefer to spend their last hours at home provided they receive adequate palliative care.

It is perceived that Arab patients prefer not to discuss advance directives. Possible factors include fear of death and all news related to that. It is our observation in a critical care setting that patients and their relatives do not seem to appreciate the prognosis of their illness. This may be due to lack of proper communication with their primary doctors or their failure to understand or request such information. Both factors can influence the desire not to embrace the concept of advance directives. Advance directives seem more accepted as a practice in the nursing home and assisted living setting, neither of which are commonly found in Arab culture (19). Our findings however suggest that Arab patients may be more willing to discuss end of life decisions and advance directives than previously thought.

Our study demonstrates that the patients participating, probably in common with all other patients with similar illnesses, lack knowledge about their primary illness and about advance planning and life-supportive 
care. It also shows that our patients are willing to engage in discussions regarding end of life care planning with their physicians and to make their own decisions about end of life care. This study further shows that the majority of patients are able to make sensible judgments about end of life decisions despite their limited knowledge of CPR or mechanical ventilation. When given direct questions regarding end of life preferences, $90 \%$ had formulated opinions on the desirability of resuscitative care.

Unfortunately, in our health care system, the issues of advance care planning preferences are rarely discussed with patients or their families. Physicians may lack the time or training to initiate end of life discussions or may be uncomfortable approaching these issues, thinking that patients will be distressed and may be unwilling to accept these discussions (20-23). Furthermore, research has shown that in about $25 \%$ of cases the physician's perception of the patient's preference was inaccurate (13). Unfortunately, we did not ask participants whether or not their physicians had discussed advance planning. Research from Western countries suggests that only about $15 \%$ of patients have the chance to discuss their end of life wishes with their physician, and only about $10 \%$ had confidence that their wishes were understood $(6,24,25)$. The physicians initiated these discussions in less than $5 \%$ of cases. In our culture, such an approach by the physician is even less likely.

Another finding of this survey is the impact on quality of life after recovery from cardiac arrest, particularly patients' perception of this, on decision-making by our patients. Quality of life is used significantly among health care providers to justify their decision to maintain or withdraw therapy. The patients surveyed were less likely to request resuscitation if they would be permanently dependent on machines or if they were likely to sustain irreversible brain damage. Involving patients' families when the issues of advance care planning are addressed allows family members to participate and better understand the patient's end of life wishes. If surrogate decision-making is required later, the patient's end of life wishes are more likely to be respected if the family has been involved in the initial discussions.

There are limitations to this study that should be considered. A study in questionnaire form is always limited by patient recall, misunderstandings of terms and patient selection. The study was done in Riyadh, the Central Region of Saudi Arabia, and results may not necessarily apply to other geographical locations or to other hospitals in Saudi Arabia or to other Arab countries.

We believe the results of this study are important in many ways. Firstly, it highlighted major deficiencies in knowledge of the natural history of illnesses and whether an illness was chronic, incurable or even terminal and the general absence of a structured programme or effort to address this lack of knowledge at national level. Secondly, we were able to demonstrate the ability and willingness of our patients to express their wishes regarding end of life care.

Funding: None.

Competing interests: None declared.

\section{Préférences en matière de directives anticipées de patients atteints de maladie chronique en phase terminale quant aux décisions de fin de vie : exemple de l'Arabie saoudite}

\section{Résumé}

Contexte : Les directives anticipées quant aux décisions de fin de vie sont peu utilisées dans les pays arabes.

Objectif : La présente étude porte sur les directives anticipées en matière de soins au sein d'un échantillon de patients arabes.

Méthodes : Il s'agissait d'une étude transversale qui a été menée entre mars 2012 et mars 2013 sur un échantillon de 300 patients atteints de maladie chronique hospitalisés au Fahad National Guard Hospital, Riyad, grand centre hospitalier de soins tertiaires d'Arabie saoudite.

Résultats : L'âge moyen des patients de l'étude était de 48,7 ans (écart type 16,4); 104 patients étaient sous hémodialyse, 73 étaient atteints d'un cancer à un stade avancé, 81 souffraient d'une maladie hépatique chronique et 35 d'une maladie respiratoire chronique. Plus de 80 \% des personnes interrogées estimaient qu'il revenait au médecin de prendre une décision quant à la réanimation cardio-respiratoire. Plus de $60 \%$ souhaitaient rester à leur domicile lorsque leur état de santé se dégraderait, annonçant un décès imminent. Aucune corrélation significative n'a été constatée entre les préférences des patients quant à la décision de fin de vie et la religiosité, la qualité de vie, la durée de la maladie ou d'autres caractéristiques démographiques.

Conclusion : Malgré un manque de connaissances notable parmi les répondants en ce qui concerne la réanimation, une majorité de patients atteints de maladie chronique étaient enclins à explorer des différentes options et ont été en mesure d'établir des plans de directives anticipées concernant leur état de santé. 


$$
\begin{aligned}
& \text { رغبات التو جيهات المسبقة للمصابين باعتلال مزمن لا يُرجّى شفاؤه بخُصوص قرار ات مرحلة الاحتضار: عينة من } \\
& \text { الشرق الأوسط } \\
& \text { سالم باهارون، محسن الزهراني، إيمان الصافي، ليلى لائقة، حمدان الجححدلي، أنور أحمد } \\
& \text { الخالاصة } \\
& \text { الخلفية: نادراً ما يكتب العرب وصغة وصآل } \\
& \text { الأهداف: هدفت هذه الدراسة إلى بحث الرغبات المسبقة الخاصة بالرعاية لدى عينة من المرضى العرب. }
\end{aligned}
$$

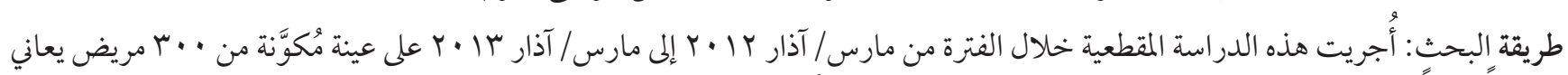

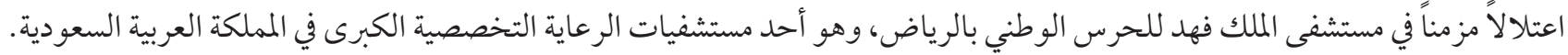

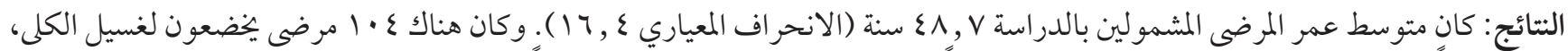

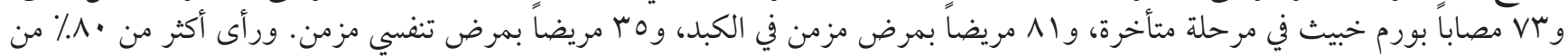

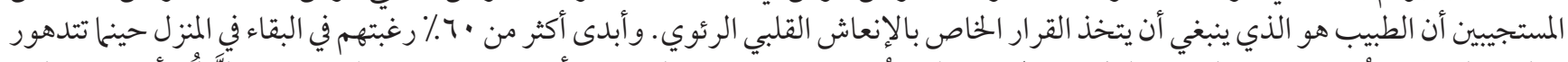

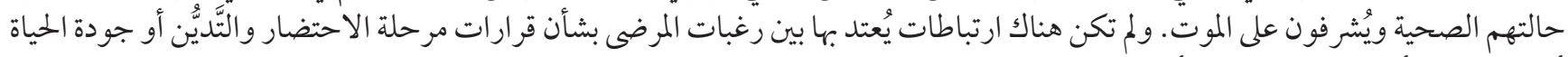

$$
\begin{aligned}
& \text { أو مدة المرض أو خصائص سكانية أخرى. }
\end{aligned}
$$

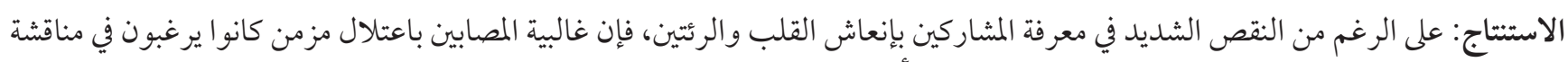

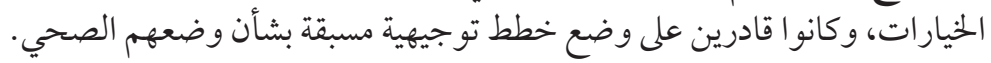

\section{References}

1. Douglas R, Brown HN. Patients' attitudes toward advance directives. J Nurs Scholarsh. 2002;34(1):61-5. PMID:11901969

2. Pfeifer MP, Sidorov JE, Smith AC, Boero JF, Evans AT, Settle MB. The discussion of end-of-life medical care by primary care patients and physicians: a multicenter study using structured qualitative interviews. The EOL Study Group. J Gen Intern Med. 1994 Feb;9(2):82-8. PMID:8164082

3. Searight HR, Gafford J. Cultural diversity at the end of life: issues and guidelines for family physicians. Am Fam Physician. 2005 Feb 1;71(3):515-22. PMID:15712625

4. Wong SY, Lo SH, Chan CH, Chui HS, Sze WK, Tung Y Is it feasible to discuss an advance directive with a Chinese patient with advanced malignancy? A prospective cohort study. Hong Kong Med J. 2012 Jun;18(3):178-85. PMID:22665680

5. Al-Jahdali H, Baharoon S, Al Sayyari A, Al-Ahmad G. Advance medical directives: a proposed new approach and terminology from an Islamic perspective. Med Health Care Philos. 2013 May;16(2):163-9. PMID:24571002

6. Kagawa-Singer M, Blackhall LJ. Negotiating cross-cultural issues at the end of life: "You got to go where he lives". Jama 2001;286(23):2993-3001. PMID:11743841

7. Sonnenblick M, Friedlander Y, Steinberg A. Dissociation between the wishes of terminally ill parents and decisions by their offspring. J Am Geriatr Soc. 1993 Jun;41(6):599-604. PMID:8505455

8. Jawa RS, Shapiro MJ, McCormack JE, Huang EC, Rutigliano DN, Vosswinkel JA. Preadmission Do Not Resuscitate advanced directive is associated with adverse outcomes following acute traumatic injury. Am J Surg. 2015 Nov;210(5):814-21. doi:10.1016/j. amjsurg.2015.04.007

9. Yen YF, Huang LY, Hu HY, Sun WJ, Ko MC, Lee YL, et al. Association of advance directives completion with the utilization of life-sustaining treatments during the end-of-life care in older patients. J Pain Symptom Manage. 2017 Sep 5. 55(2):265-71.

10. Allen SL, Davis KS, Rousseau PC, Iverson PJ, Mauldin PD, Moran WP. Advanced care directives: overcoming the obstacles. J Grad Med Educ. 2015 Mar;7(1):91-4. doi:10.4300/JGME-D-14-00145.1

11. Pangman VC, Sloan J, Guse L. An examination of psychometric properties of the Mini-Mental Status Examination and the Standardized Mini-Mental Status Examination: implications for clinical practice. Appl Nurs Res 2000;13(4):209-13. doi:10.1053/ apnr.2000.9231

12. Albanna M, Yehya A, Khairi A, Dafeeah E, Elhadi A, Rezgui L, et al. Validation and cultural adaptation of the Arabic versions of the Mini-Mental Status Examination - 2 and Mini-Cog test Neuropsychiatr Dis Treat. 2017 Mar 14;13:793-801. doi:10.2147/NDT. S126825

13. Gusi N, Olivares PR, Rajendram R. The EQ-5D health-related quality of life questionnaire. In: Preedy VR, Watson R, eds. Handbook of disease burdens and quality of life. New York Springer; 2010:87-99.

14. Feng Y, Devlin N, Herdman Mi Assessing the health of the general population in England: how do the three- and five-level versions of EQ-5D compare? Health Qual Life Outcomes. 2015;13:171. doi:10.1186/s12955-015-0356-8 
15. Sakthong P, Sonsa-Ardjit N, Sukarnjanaset P, Munpan W Psychometric properties of the EQ-5D-5L in Thai patients with chronic diseases Qual Life Res. 2015 Dec;24(12):3015-22. doi:10.1007/s11136-015-1038-z

16. Gouda A, Alrasheed N, Ali A, Allaf A, Almudaiheem N, Ali Y, et al. Knowledge and attitude of ER and intensive care unit physicians toward do-not-resuscitate in a tertiary care centre in Saudi Arabia: a survey study. Indian J Crit Care Med. 2018 Apr;22(4):214-222. doi:10.4103/ijccm.IJCCM_523_17

17. Amoudi AS, Albar MH, Bokhari AM, Yahya H, Merdad AA Perspectives of interns and residents toward do-not-resuscitate policies in Saudi Arabia. Adv Med Educ Pract. 2016 Mar 14;7:165-70. doi:10.2147/AMEP.S99441

18. Rahman M, Arabi Y, Adhami N, Parker B, Al Malik S, Al Shimemeri A. Current practice of Do-Not-Resuscitate (DNR) orders in a Saudi Arabian tertiary care centre. Crit Care. 2001;5(Suppl 1):P257 doi:10.1186/cc1322

19. Daaleman TP, Williams CS, Preisser JS, Sloane PD, Biola H, Zimmerman S. Advance care planning in nursing homes and assisted living communities. J Am Med Dir Assoc. 2009 May;10(4):243-51. doi:10.1016/j.jamda.2008.10.015

20. Kelner M, Bourgeault IL, Hebert PC, Dunn EV. Advance directives: the views of health care professionals. CMAJ 1993;148(8):13318. PMID:8462055

21. Weiner JS, Arnold RM, Curtis JR, Back AL, Rounsaville B, Tulsky JA. Manualized communication interventions to enhance palliative care research and training: rigorous, testable approaches. J Palliat Med. 2006 Apr;9(2):371-81. doi:10.1089/jpm.2006.9.371

22. Connors AF, Dawson NV, Desbiens NA, Fulkerson WJ, Goldman L, Knaus WA, et al. A controlled trial to improve care for seriously ill hospitalized patients. The study to understand prognoses and preferences for outcomes and risks of treatments (SUPPORT). The SUPPORT Principal Investigators. JAMA 1995;274(20):1591-8.

23. Krumholz HM, Phillips RS, Hamel MB, Teno JM, Bellamy P, Broste SK, et al. Resuscitation preferences among patients with severe congestive heart failure: results from the SUPPORT project. Study to understand prognoses and preferences for outcomes and risks of treatments. Circulation. 1998;98(7):648-55. PMID:9715857

24. Joos SK, Reuler JB, Powell JL, Hickam DH. Outpatients' attitudes and understanding regarding living wills. J Gen Intern Med. 1993 May;8(5):259-63. PMID:8505685

25. Matsumura S, Bito S, Liu H, Kahn K, Fukuhara S, Kagawa-Singer M, et al. Acculturation of attitudes toward end-of-life care: a cross-cultural survey of Japanese Americans and Japanese. J Gen Intern Med. 2002 Jul;17(7):531-9. 